\title{
Angina pectoris with normal coronary arteries in Shy-Drager syndrome
}

\author{
R U T H S L VER B ER G, Y A A K O N A P A R T EK, \\ B ASILS. LEW IS, A N M ICHA LEVY
}

From the Departments of Neurology, Medicine A, and Cardiology, Hadassah University Hospital, Jerusalem, Israel

SUMMARY A patient with Shy-Drager syndrome who presented with severe angina pectoris is described. Special investigations of his autonomic nervous system showed sympathetic and parasympathetic dysfunction with supersensitive end-organ response. Sympathetic dysfunction manifested as labile hypertension, severe postural hypotension, and inadequate heart rate response to atropine and the Valsalva manoeuvre. These changes in blood pressure were accompanied by severe disabling angina pectoris. Selective coronary angiography showed normal coronary arteries. It is suggested that angina pectoris resulted from the inadequate circulatory response and is another clinical manifestation of the Shy-Drager syndrome.

The combination of extrapyramidal signs and autonomic system dysfunction is the hallmark of the syndrome described by Shy and Drager (1960). Autonomic dysfunction includes orthostatic hypotension, anhidrosis, iris atrophy, impotence, atonic bladder, and loss of rectal sphincter tone. Inadequate circulatory responses to the Valsalva manoeuvre, exercise, hyperventilation, and supersensitivity to infusion of catecholamines are characteristic of the syndrome (DeJong, 1970; Klutzow et al., 1975; Davies et al., 1978).

We describe a patient with the Shy-Drager syndrome suffering from severe angina pectoris in whom selective coronary angiography showed normal coronary arteries. We suggest that the angina pectoris was caused by changes in blood pressure as a result of autonomic nervous system dysfunction and is another clinical manifestation of the syndrome.

\section{Case report}

A 61 year old man had a two year history of recurrent episodes of syncope, progressive impotence, urinary incontinence and, during the three months before admission to hospital, severe angina pectoris related to changes of posture and

Address for reprint requests: Dr Yaakov Naparstek, Department of Medicine A, Hadassah University Hospital, PO Box 499, Jerusalem, Israel.

Accepted 27 February 1979 mild physical exertion. In addition he had slow ness of movement, a resting tremor in the uppes limbs, and disturbances of gait. On examination the pulse rate was regular, 68 per minute, bloo 8 pressure $160 / 85 \mathrm{mmHg}$ in the supine position Immediately upon standing, the blood pressure dropped to $75 / 60 \mathrm{mmHg}$ with no compensator rise in the pulse rate, and the patient complained of anginal pain. There were no signs of heart failure. Hypomimia, as well as a mild resting tremor, increased muscle tone, inco-ordination of limbs, and an unsteady gait were noted.

Routine blood tests including complete blood count, serum electrolytes, blood urea nitrogen, glucose, liver function tests, calcium, phosphorus, acid phosphatase, cholesterol, triglycerides, serum cortisol, vitamin B12, folic acid, VDRL, and glucose tolerance tests were normal. Urinary excretion of 17-hydroxy- and keto-steroids were normal. The electrocardiogram was normal at rest and showed minor flattening of the $T$ wave in leads V5 and V6 during chest pain. A treadmill test had to be discontinued after three minutes because of weakness, dizziness, and chest discomfort with a fall in blood pressure from $100 / 80 \mathrm{mmHg}$ to $80 / 60 \mathrm{mmHg}$. The heart rate at this time was 126 beats $/ \mathrm{min}$. Skull and chest radiographs, and intravenous pyelograms, including post-voiding films, were normal. Electroencephalogram and computerised tomography of the brain were also normal. 
Cardiac catheterisation and coronary angiography were performed for detailed study of the autonomic nervous system and to investigate further the cause of the severe angina pectoris. The following interventions were performed: (1) to test the baroreceptors, change of body position, carotid sinus massage and Valsalva manoeuvre were used; (2) to test central integration of the pathways and sympathetic outflow, the Valsalva manoeuvre and intravenous injection of atropine (2.5 mg) were used; (3) to test the end-organ response, ephedrine $(25 \mathrm{mg})$ was given orally.

\section{Result of special studies}

There was marked postural hypotension without a compensatory rise in heart rate on standing (Table). Carotid massage produced bradycardia with a decrease in heart rate from 75 to 52 beats/ min, indicating a normal vagal response. The response to the Valsalva manoeuvre was abnormal (Fig. 1). There was virtually no change in heart rate in response to the hypotension which occurred in phase 3, and there was no overshoot in blood pressure nor reflex bradycardia in phase 4 . A hypertensive response was observed after ingestion of $25 \mathrm{mg}$ ephedrine-the blood pressure rose from $110 / 70$ to $180 / 100 \mathrm{mmHg}$ while the pulse rate showed almost no change. Intravenous injection of atropine produced very little change in heart rate, and after $2.5 \mathrm{mg}$ (given in $0.5 \mathrm{mg}$ boluses every three minutes) the heart rate increased from 90 to 110 beats $/ \mathrm{min}$. These abnormalities indicate inadequate sympathetic function and exaggerated end-organ response.

Coronary angiography, performed in multiple oblique views using the Judkin's technique and filming at 25 and 50 frames/second with a 4.5 inch image intensifier, showed normal coronary arteries (Fig. 2). Left ventriculography showed that the

Table Results of autonomic nervous system studies

\begin{tabular}{|c|c|c|c|c|}
\hline \multirow[t]{2}{*}{ Intervention } & \multicolumn{2}{|c|}{ Before intervention } & \multicolumn{2}{|c|}{ After intervention } \\
\hline & $\begin{array}{l}\text { Heart } \\
\text { rate } \\
\text { beats/min }\end{array}$ & $\begin{array}{l}\text { Blood } \\
\text { pressure } \\
\mathrm{mmHg}\end{array}$ & $\begin{array}{l}\text { Heart } \\
\text { rate } \\
\text { beats/min }\end{array}$ & $\begin{array}{l}\text { Blood } \\
\text { pressure } \\
\mathrm{mmHg}\end{array}$ \\
\hline Standing & 68 & $\begin{array}{l}168 / 85 \\
\text { (supine) }\end{array}$ & 68 & $75 / 60$ \\
\hline $\begin{array}{l}\text { Carotid massage } \\
\text { Valsalva manoeuvre }\end{array}$ & 75 & $215 / 70$ & 52 & $210 / 80$ \\
\hline Phase 1 & 87 & $215 / 70$ & 80 & $255 / 130$ \\
\hline Phase 2 & 87 & $215 / 70$ & 88 & $165 / 115$ \\
\hline Phase 3 & 87 & $215 / 70$ & 88 & $120 / 75$ \\
\hline Phase 4 & 87 & $215 / 70$ & 82 & $190 / 80$ \\
\hline $\begin{array}{l}\text { Ephedrine } 25 \mathrm{mg} \\
\text { orally }\end{array}$ & 75 & $110 / 70$ & 78 & $180 / 100$ \\
\hline $\begin{array}{l}\text { Atropine } 2.5 \mathrm{mg} \\
\text { intravenously }\end{array}$ & 90 & $100 / 70$ & 110 & $110 / 75$ \\
\hline Treadmill effort test & 88 & $100 / 80$ & 126 & $80 / 60$ \\
\hline
\end{tabular}

left ventricle was normal in size and contracted well.

\section{Treatment}

The patient received 9-fluoro-cortisone acetate $0.2 \mathrm{mg}$ daily and wore elastic stockings without any effect on the blood pressure. Ephedrine ( $25 \mathrm{mg}$ daily) resulted in a rise of the supine blood pressure from $110 / 60 \mathrm{mmHg}$ to $180 / 100$ $\mathrm{mmHg}$, but did not relieve the orthostatic hypotension $(70 / 55 \mathrm{mmHg})$. An antigravity suit was used at a pressure of $40 \mathrm{mmHg}$. This prevented the fall in blood pressure as well as the symptomatology of angina pectoris and dizziness on change of body position. However, the suit was impractical for everyday use and was rejected by the patient. Dipyridamole $(75 \mathrm{mg}$ three times daily), isosorbide dinitrate $(10 \mathrm{mg}$ three times daily), and nitroglycerine (2.6 $\mathrm{mg}$ three times daily) did not relieve the angina but seemed to aggravate it.

\section{Discussion}

Our patient presented with the typical picture of the Shy-Drager syndrome including autonomic and extrapyramidal dysfunction. Sympathetic disorders manifested as orthostatic hypotension, impaired response to the Valsalva manoeuvre, inadequate response to atropine as well as hypotension on physical exertion. Nonetheless the patient was able to achieve a moderate increase in heart rate during effort testing. The blood vessels were found to be supersensitive to small quantities of ephedrine, consistent with the denervation supersensitivity observed in the ShyDrager syndrome (Meyer et al., 1973). In our patient ephedrine did not prevent orthostatic hypotension. Although treatment with sympathomimetic drugs is sometimes successful in preventing orthostatic hypotension, this is often achieved at the expense of supine hypertension and tachycardia (Davies et al., 1978). The pressure suit did succeed in preventing orthostatic hypotension, but was too cumbersome to be practical. Impotence was the main feature of parasympathetic dysfunction. The patient also suffered from severe urgency, often accompanied by urinary incontinence. Nevertheless, his bladder was of normal size and there was no residue on voiding. This picture is not compatible with a parasympathetic lesion but seems to fall into the category of "disinhibited bladder" (DeJong, 1970).

The distinguishing feature of this patient was 


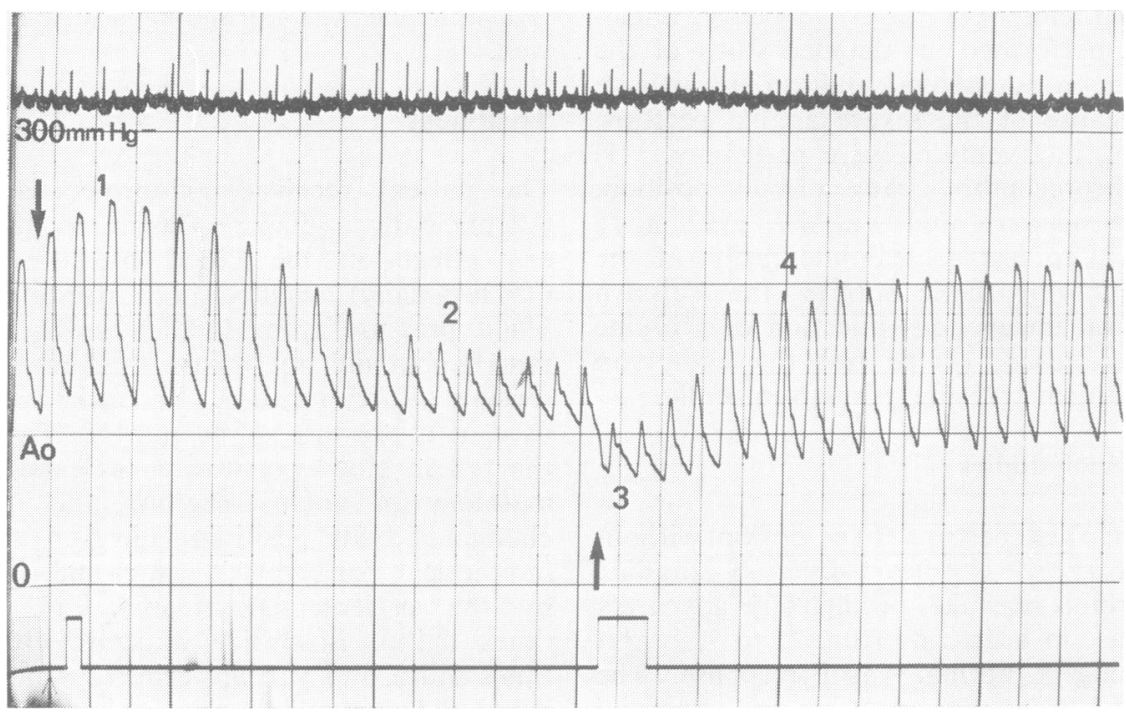

Fig. 1 Intra-arterial pressure recording from the ascending aorta $\left(A_{n}\right)$ during the Valsalva manoeuvre. The arrows indicate the onset and end of the manoeuvre. There is a normal increase in pressure in phase 1 and a normal decrease in pressure during phases 2 and 3, but reflex tachycardia does not occur. After release of the Valsalva manoeuvre overshoot hypertension and bradycardia do not occur (phase 4.)
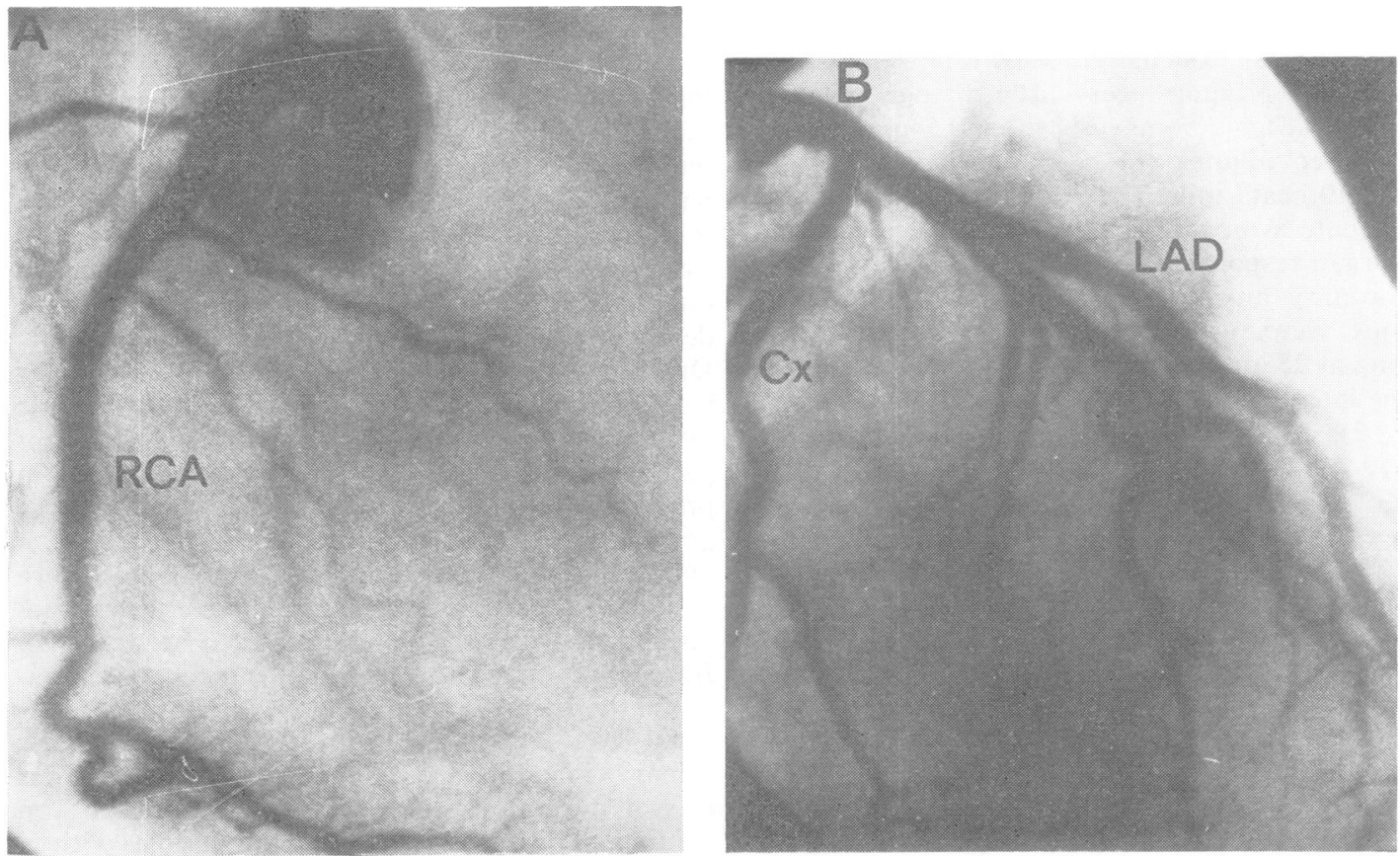

Fig. 2 Selective coronary arteriogram. (A) Right coronary artery $(R C A)$ is normal (left anterior oblique view). (B) Left coronary arteriogram (right anterior oblique view) shows a normal left main stem and virtually normal left anterior descending $(L A D)$ and circumflex $(C x)$ branches with trivial, nonobstructive atheroma in the circumflex system. 
the severe angina pectoris which appeared on change of body position or minimal exertion in the presence of normal coronary arteries. Although $9 \%$ of patients with angina pectoris have normal coronary arteriograms (Schlant, 1974), it is likely that in the present case, angina was related to the hypotension which appeared on standing or during physical exertion. Moreover, vasodilators such as dipyridamole and isosorbide dinitrate which normally alleviate the chest pain of coronary artery disease were ineffective and aggravated his condition. We suggest that angina pectoris may be another symptom of the inadequate circulatory response in the Shy-Drager syndrome.

We thank Dr Bentwich for referring the patient and Ms G. Obstfeld for technical assistance.

\section{References}

Davies, B., Bannister, R., and Sever, P. (1978). Pressor amines and monoamine oxidase inhibitors for treatment of postural hypotension in autonomic failure. Lancet, 1, 172-175.

DeJong, R. N. (1970). The Neurologic Examination, third edition, pp. 730-731. Harper and Row: New York.

Klutzow, F. W., Earle, K. M., and Webster, D. D. (1975). Disorders of autonomic function. Military Medicine, 140, 338-344.

Meyer, J. S., Shinazu, K., Fukuuchi, Y., Ohachi, T., Okanoto, S., Koto, A., and Ericsson, A. D. (1973). Central dysautoregulation in central neurogenic hypotension (Shy-Drager syndrome). Neurology (Minneapolis), 23, 262-273.

Schlant, R. C. (1974). Altered cardiovascular physiology of coronary atherosclerotic heart disease. In Heart, Arteries and Veins, pp. 1022. Edited by J. W. Hurst. McGraw-Hill Kogakuaha Ltd: Tokyo.

Shy, G. M., and Drager, G. A. (1960). A neurological syndrome associated with orthostatic hypotension. Archives of Neurology (Chicago), 2, 511-527. 